\title{
INTENCIONES DE TURISTAS POTENCIALES REGIONALES PARA VIAJAR AL ESTADO DE COLIMA, EN EL CONTEXTO POS-COVID-19
}

\author{
CARLOS MARIO AMAYA MOLINAR \\ cmamaya@ucol.mx \\ RENATO FRANCISCO GONZÁLEZ SÁnCHEZ \\ refragosa67@gmail.com \\ IRMA MAGAÑA CARRILLO \\ irma@ucol.mx \\ Universidad de Colima, Colima, México
}

Este trabajo busca conocer las intenciones de viaje potenciales en el área de influencia turística de Colima, México. Se utilizaron 495 cuestionarios que permitieron desarrollar una base de datos a fin de generar información descriptiva y realizar análisis de correspondencias. Los encuestados muestran cautela de viajar frente a los riesgos sanitarios, la situación económica y la inseguridad. El trabajo se basa asimismo en la literatura académica sobre temas de mercadotecnia, manejo de desastres y competitividad turística. Se formulan propuestas para la recuperación de la actividad turística en Colima al final de la pandemia.

Palabras clave: COVID-19, destino turístico, sociodemográfico, hábitos, correspondencias.

\section{TRAVEL INTENTIONS TO A REGIONAL TOURIST DESTINATION IN THE POS-COVID-19 CONTEXT: THE CASE OF COLIMA, MEXICO}

This work seeks to know the travel intentions of potential tourists in the area of tourist influence of Colima, Mexico. 495 questionnaires allowed to develop a database in order to generate descriptive information and perform correspondence analysis. Respondents show caution to travel in the face of health risks, the economic situation and insecurity. The work is also based on the academic literature on marketing, disaster management and tourism competitiveness issues. Proposals are made for the recovery of tourist activity in Colima at the end of the pandemic.

Keywords: COVID-19, tourist destination, sociodemographic, habits, correspondences.

CÓMO CITAR: Amaya, C., González, R. y Magaña, I. (2020). Intenciones de turistas potenciales regionales para viajar al estado de Colima, en el contexto pos-COVID-19. Dimensiones Turísticas [Número especial: Turismo y COVID-19], 4, 149-178. https://doi.org/10.47557/THLB4755 


\title{
Introducción
}

\begin{abstract}
(2) I objetivo central del estudio es conocer las intenciones de viaje potenciales en la zona de influencia turística del estado de Colima, al término de la emergencia sanitaria generada por el COVID-19, obteniendo información para estimar la demanda de servicios afines en la entidad, con miras al segundo semestre del año 2020. Específicamente, el trabajo se orienta a identificar percepciones y expectativas del turista sobre las características de los viajes al término del confinamiento establecido por el gobierno estatal, generando datos de utilidad para los actores del sector turismo en la entidad, dirigidos a superar la profunda crisis generada por la pandemia.
\end{abstract}

Se realizó un trabajo colaborativo entre la Universidad de Colima (UCOL) y la Secretaría de Turismo del estado, con la participación de operadores y empresarios del ramo, quienes manifestaron su disposición de contribuir con la investigación diseñada por el Cuerpo Académico UCO-CA 060, "Estudios de Turismo y Competitividad", de la Facultad de Turismo. Con ello, se busca aprovechar el conocimiento académico para apoyar la recuperación operacional de la actividad local frente a la emergencia sanitaria y económica, en respuesta a la solicitud de las autoridades locales del ramo.

La información recopilada arrojó datos respecto al perfil sociodemográfico de la clientela turística del destino Colima, sus hábitos de viaje y expectativas pospandemia. El Análisis de Correspondencias (AC) permitió establecer correlaciones entre diversas variables del perfil sociodemográfico y los hábitos de viaje de la muestra encuestada. Desde el punto de vista de la rivalidad de destinos turísticos, se logró ubicar el posicionamiento de Colima frente a otros competidores, en función de un conjunto de indicadores básicos. En términos de literatura académica, el documento se apoya igualmente en fundamentos relacionados con el perfil sociodemográfico del turista, hábitos de viaje, la segmentación de mercados y la competitividad de los destinos.

En la primera parte del trabajo se mencionan antecedentes de crisis económicas y sanitarias, ocurridas durante el presente siglo; enseguida, se abordan fundamentos teóricos relacionados con las variables incluidas. El tercer apartado aborda la metodología empleada para realizar el estudio empírico, tanto en su parte descriptiva como en el AC. Los resultados obtenidos se presentan en el apartado 4 y se discuten en la sección 5. Las conclusiones son complementadas con implicaciones para la gestión de los destinos turísticos y se mencionan algunas de las limitaciones del trabajo. 


\section{Impacto de crisis y pandemias en la actividad turística en el siglo XXI}

En las últimas décadas, el sector turismo se ha visto expuesto a crecientes impactos económicos y sociales, debido a desastres naturales tales como eventos climáticos extremos o desastres naturales de origen humano, así como por la diversidad de riesgos de salud debido al esparcimiento de enfermedades infecciosas. De acuerdo con el World Travel \& Tourism Council (WTTC, 2019), el paisaje de riesgos se está transformando, con nuevas amenazas que están reconfigurando continuamente el ecosistema global. Estos riesgos van desde tensiones geopolíticas y económicas por eventos como guerras y terrorismo, hasta contingencias globales de salud y crecientes amenazas ambientales.

Se ha documentado ampliamente el doble papel que juega el turismo en el contexto de las pandemias; por un lado, debido a las restricciones sanitarias, la mayoría de ellas han pausado el desarrollo de la actividad y, en consecuencia, se han producido cambios negativos en la economía de las empresas y destinos, así como en las sociedades anfitrionas (Kuo et al., 2009; Monterrubio, 2010; Rassy y Smith, 2013). Por otro lado, se reconoce que el turismo tiene un rol importante en la propagación de las enfermedades contagiosas (Wilder-Smith, 2006), debido a las altas concentraciones de personas en los sistemas de transporte masivo como los aviones, cruceros, autobuses, así como en las instalaciones turísticas.

En lo que va del siglo XXI, este tipo de pandemias se ubican como uno de los principales riesgos de salud, resultante de la dispersión de nuevas enfermedades que cruzan fronteras internacionales, afectando a un gran número de personas. En el caso de las gripes, acorde con la Organización Mundial de la Salud (OMS, 2010) se convierten en pandemia cuando surgen nuevos virus que se propagan por el mundo y la mayoría de las personas no tienen inmunidad contra ellos. Se han identificado al menos siete pandemias desde el año 2002 (tabla 1), con impactos en las sociedades y economías de diversas regiones del mundo; de ellas, cinco han sido de origen gripal, del tipo Síndrome respiratorio agudo severo (SARS). 


\section{Tabla 1. Pandemias del siglo XXI}

\begin{tabular}{|c|c|}
\hline Año & Pandemia \\
\hline 2002 & Síndrome respiratorio agudo severo SARS-CoV \\
\hline 2005 & La gripe aviaria en su cepa H5N1 \\
\hline $2009-2010$ & Pandemia de gripe AH1N1 \\
\hline $2012-2015$ & Síndrome respiratorio de Oriente Medio \\
\hline 2014 & Epidemia de ébola \\
\hline 2014 & Virus del Zika \\
\hline $2019-2020$ & COVID-19 (SARS-CoV 2) \\
\hline
\end{tabular}

Fuente: Elaboración propia con datos de la Organización Mundial de la Salud $(2010,2020)$ y la Organización Panamericana de la Salud (2009).

\subsection{Contexto Económico}

El Fondo Monetario Internacional (FMI, 2020) muestra datos de crecimiento global del Producto Interno Bruto (PIB) de 2.9\% durante el año 2019, con un pronóstico para el 2020 de $-4.9 \%$. El brote epidémico del COVID-19 y su evolución a pandemia global transformó el panorama internacional drásticamente. Aunado al padecimiento de parte de la población y la lamentable pérdida de vidas humanas en todo el mundo, la enfermedad ha traído retos sin precedentes en materia de los sistemas de salud, la economía y la situación financiera de las empresas y de los gobiernos.

Las medidas sanitarias para mitigar los efectos del COVID-19 han sido severas, provocando la suspensión temporal en sectores no esenciales, incidiendo en la virtual interrupción intemepestiva de actividades en el sector turismo. Además del desconocimiento de la duración de la pandemia y de la posible existencia de nuevos brotes, la implementación de estas medidas ha aumentado la incertidumbre. Frente a esta situación, las perspectivas de crecimiento mundial se han revisado de manera continua a la baja, manteniendo riesgos elevados hacia una mayor contracción (FMl, 2020).

Las perspectivas de una recesión a nivel global han provocado una reducción en la demanda de energéticos y de materias primas, generando una disminución en sus precios. En línea con las perspectivas de recesión a nivel global, la actividad económica en México durante el primer trimestre de 2020, presentó un retroceso de 1.6\% con respecto al cuarto trimestre de 2019 (Secretaría de Hacienda y Crédito Público, SHCP, 2020). Adicionalmente, se han observado significativos episodios de volatili- 
dad en los mercados financieros internacionales como consecuencia de la elevada incertidumbre, desencadenando una mayor aversión al riesgo. Lo anterior se ha reflejado en una reducción en la demanda de activos de economías emergentes y en el consecuente aumento en la búsqueda de activos seguros.

Al interior, se observa un incremento de $0.5 \%$ en el sector primario, mientras que los sectores secundario y terciario se redujeron en $1.4 \%$. Debe mencionarse que esta variación trimestral en el PIB es menor en magnitud a la observada en el primer trimestre de 1995, cuando hubo una contracción de $5.7 \%$, y a la registrada en el primer trimestre de 2009, en el que hubo una caída de $5.1 \%$. A pesar de ello, de enero a marzo se advirtieron datos que reflejan un mercado interno sólido y resistente: se generaron 190 mil 421 puestos de trabajo formales permanentes en los diversos sectores de la economía nacional respecto al mismo periodo de 2019 (SHCP, 2020).

En un análisis de las perspectivas para el año 2020, el Consejo Nacional Empresarial Turístico (CNET, 2020) estima para México una reducción en el consumo del sector, de 1.6 billones de pesos; una contracción estimada en $49.3 \%$ con relación al año previo. Dicha cantidad es equivalente al $25 \%$ de todo el Presupuesto de Egresos de la Federación para el año en curso, que permitiría construir el equivalente a 11 Trenes Mayas y ocho Refinerías Dos Bocas. En otras palabras, el quebranto del turismo, por falta de visitantes, equivale a 4.1 mil millones de pesos.

Con ello, el PIB turístico se reduciría a una participación estimada en el PIB nacional de $4.9 \%$, frente a una proporción del $8.7 \%$ en el 2018. En un entorno en que las estimaciones de reducción del PIB nacional se encuentran alrededor del 7.0\%, parte importante de la contracción se explicaría por el derrumbe del sector turístico, en el que se estima, además, una pérdida del $27 \%$ del empleo formal, poco más de un millón de personas perdería su trabajo a consecuencia de la contingencia sanitaria (CNET, 2020).

\subsection{Implicaciones de la pandemia para la industria turística colimense}

El estado de Colima no es ajeno al contexto económico mencionado; la Cámara Nacional de la Industria Restaurantera y Alimentos Condimentados en la entidad (CANIRAC) reporta que el $12 \%$ de los restaurantes que se vieron obligados a suspender operaciones durante el mes de junio no podrá seguir adelante, con la expectativa de que en el mes de julio esta proporción pudiera aumentar al 50\%. Se 
estima que el sector restaurantero logrará recuperarse a mediados del 2021 (EI Comentario, 2020).

La Asociación de Hoteles y Moteles del estado de Colima informa que las empresas de hospedaje han dejado de percibir alrededor de 900 millones de pesos a consecuencia de la pandemia, señalando que a partir del 1 de julio los establecimientos adoptarían todas las medidas y protocolos necesarios para la seguridad del turista. La aerolínea Aeromar registró una disminución de frecuencias de vuelos cercana al 90\% desde el decreto de la emergencia sanitaria por el COVID-19 (Cázares, 2020).

Así, Colima espera para este año 2020 una reducción sustancial del consumo turístico, disminución del PIB, pérdida de empleo y caída en la inversión por parálisis de la economía e inestabilidad de los mercados, así como una menor recaudación de impuestos, migración de empresas a la informalidad, cierre de negocios y disminución drástica de utilidades.

El estado no puede considerarse altamente competitivo frente a otras entidades o a otros destinos destacados. La información de la tabla 2 muestra las limitaciones del sector turismo colimense en algunos de los indicadores básicos de la industria; destaca el rezago en la recepción de visitantes internacionales, lo cual obedece básicamente a que el gobierno de los Estados Unidos de América recomienda a sus ciudadanos que no visiten este estado mexicano, debido a elevados niveles de violencia e inseguridad (Oficina de Asuntos Consulares, 2020). A pesar de contar con valiosos recursos turísticos naturales y culturales, la competitividad turística de Colima es una asignatura pendiente.

Tabla 2. Indicadores de actividad turística en Colima y destinos competidores, 2018

\begin{tabular}{|c|c|c|c|}
\hline Indicador & Colima & Jalisco & Quintana Roo \\
\hline Visitantes & 1294460 & 9015018 & 16675407 \\
\hline Proporción turistas internacionales & $4 \%$ & $17 \%$ & $74 \%$ \\
\hline Habitaciones hoteleras & 8283 & 75422 & 100986 \\
\hline Tasa de ocupación hotelera & $47.20 \%$ & $57.49 \%$ & $76.10 \%$ \\
\hline
\end{tabular}

Fuente: Datatur (2020). 


\section{Hábitos de viaje, competitividad y lealtad a los destinos turísticos}

El conocimiento del perfil sociodemográfico, los hábitos de viaje y la lealtad de los visitantes a un destino turístico tiene notables repercusiones en la gestión de la mercadotecnia, en el posicionamiento frente a sus competidores y en el impacto económico generado por la actividad en términos de gasto, derrama económica y generación de empleos e impuestos, entre otros aspectos.

La información presentada nos muestra que el estado de Colima no se puede considerar afectado por un exceso de turistas (en sus vertientes naturales o sociales); sin embargo, desde la perspectiva económica, la industria turística sí juega un papel relevante en la entidad. El turismo se encuentra entre aquellas actividades que generan mayor empleo y derrama en las economías locales. Bunghez (2016) analiza el efecto multiplicador del gasto de los turistas en los destinos receptores, señalando que los recursos ingresados por ellos generan impactos económicos directos, indirectos e inducidos, a través de su circulación a lo largo de varios ciclos; estos recursos son gastados y reciclados por la población local en diversos circuitos.

Los trabajos de Zieba (2017) y Svensson et al. (2011) proponen que los destinos turísticos deben concentrarse en atraer aquellos segmentos de visitantes con mayor gasto y derrama económica; para este fin, identifican las siguientes variables: procedencia, perfil sociodemográfico, hábitos y motivos de viaje, y lealtad. El análisis del gasto del turista establece correlaciones generales entre estas variables: un mayor ingreso de los visitantes les permite ejercer igualmente un mayor gasto en el destino; mientras más días permanece un visitante en su estancia, aumenta su consumo y, de la misma manera, mientras más grande es el tamaño del grupo de viaje, crecerá su egreso (Thrane y Farstad, 2011; Barros y Machado, 2010). Un apropiado ejercicio de segmentación de la clientela potencial, por parte de los encargados de la comercialización de un destino turístico, contribuye a un mejor aprovechamiento de los esfuerzos de mercadotecnia, impulsando su competitividad (Dolnicar et al., 2018; Camilleri, 2018).

La lealtad es una variable esencial en la mercadotecnia y la competitividad de los destinos turísticos; su magnitud se refleja en la cantidad de veces que un turista repite su visita, en las intenciones de regresar y en su disposición para recomendarlo (Chen y Chen, 2010). La literatura académica establece una relación directa de la lealtad con la calidad, satisfacción y valor percibido en la experiencia de visita; en general, la lealtad influye positivamente en las utilidades de los negocios a través 
del incremento de los ingresos, disminución en costos de adquisición de clientes, menor sensibilidad a precios y reducción de costos de mercadotecnia (Oliver, 1999; Kotler et al., 2014).

Por definición, los estudios de competitividad frecuentemente comparan resultados de diversos destinos turísticos (Vu y Turner, 2011; Croes, 2011). Los trabajos sobre el tema utilizan un conjunto de indicadores y variables para su medición. Algunos de los que se aplican con más frecuencia son: a) el número de visitantes (Mazanec y Ring, 2011; Vu y Turner, 2011); b) la tasa de ocupación hotelera (Ivars et al., 2013; Dupeyras y MacCallum, 2013), y c) la lealtad, las intenciones conductuales positivas y el apego al destino turístico (Pike, 2012; Chen y Phou, 2013; Caber et al., 2012).

\section{Metodología del estudio empírico}

La encuesta de intenciones de viaje en zonas emisoras se realizó mediante un cuestionario electrónico, desarrollado en la aplicación de formularios de Google, enfocado en obtener información sobre las siguientes variables: perfil sociodemográfico, hábitos de viaje, intenciones de viaje pospandemia, y lealtad a Colima como destino turístico.

El cuestionario diseñado por el equipo de investigación fue validado por funcionarios de la Secretaría de Turismo de Colima y por empresarios turísticos de la entidad. Una vez aceptado el diseño, se hizo llegar a los encuestados vía internet, a través de correo electrónico y mediante redes sociales como WhatsApp. El levantamiento se llevó a cabo del 21 al 29 de mayo de 2020, se utilizó la técnica de muestreo en cadena o "bola de nieve", definido como un procedimiento de muestreo no probabilístico, utilizado para contactar sujetos potenciales cuando son difíciles de encontrar. Hanage et al. (2020) consideran que esta modalidad de muestreo puede ser una forma más eficiente de lograr una potencia estadística más que el muestreo aleatorio.

Para aplicar la técnica se acordó que la comunidad académica de la Facultad de Turismo de la Universidad de Colima y el personal de la Secretaría de Turismo enviaría el cuestionario a familiares y amigos radicados en localidades fuera de la entidad. Por su parte, los dirigentes de las organizaciones hoteleras utilizaron las bases de datos de sus clientes para distribuir el cuestionario. El procedimiento permitió reunir un total de 494 cuestionarios. El esquema de muestreo propuesto es el simple por proporciones, cuya fórmula es: 


$$
n=\frac{N * Z_{\alpha}^{2} * p * q}{d^{2} *(N-1)+Z_{\alpha}^{2} * p * q}
$$

Donde $\mathrm{N}=1$ millón 294 mil 460 visitantes a Colima en 2018; $\mathrm{p}=\mathrm{q}=0.5$, que es la proporción sugerida cuando se desconocen las características de la población; = 1.96 y $d=0.0441$ que es la precesión. Se obtuvieron 491 cuestionarios útiles, una vez que se eliminaron los incompletos.

Con las respuestas obtenidas se generó una base de datos que permitió procesar los datos en dos modalidades: en primer lugar, un análisis univariado de información descriptiva y, enseguida, un análisis relacional de variables. Las variables incluidas en el cuestionario se refieren a datos sociodemográficos, hábitos de viaje, intenciones de viaje pospandemia, y lealtad a Colima como destino turístico.

Para el análisis relacional de variables se emplean dos métodos estadísticos: análisis de correspondencias (AC) y la correlación Tau B y $C$ de Kendall. Estos métodos se aplican a variables categóricas, ordinales y/o nominales, como es el caso de las variables que caracterizan la base de datos de esta investigación.

El AC permite identificar aquellos elementos de variables discretas o categóricas que presentan cierta cercanía, indicando la existencia de relaciones entre las diversas variables incluidas en la encuesta. De acuerdo con Salvador-Figueras (2003), el AC es una técnica estadística que gráficamente muestra las relaciones de dependencia que existen entre las modalidades (o elementos) de dos o más variables categóricas, a partir de la información que brindan las frecuencias en sus tablas cruzadas.

El AC permite conocer qué elementos de variables discretas o categóricas presentan cierta cercanía. Sin embargo, el primer aspecto que este análisis indica es si dichas variables están relacionadas. En este sentido, primero muestra una prueba de Ji-Cuadrada $\left(X^{\wedge} 2\right)$, cuya hipótesis nula $(\mathrm{H} 0)$ es que no existe relación entre las variables categóricas. La regla de decisión para contrastar a la hipótesis nula se basa en la confianza (o significancia estadística) establecida entre el 90 y $99 \%$. Un indicador de la dispersión de la nube de puntos es la inercia (Aldás y Uriel, 2017), en la medida que la inercia total aumente, más dependientes son las variables categóricas, con lo cual cobra más sentido inspeccionar qué elementos de las variables se acercan entre sí.

Como las variables socioeconómicas y de intenciones de viajar son categóricas y ordinales, lo que implica que no son continuas (diferenciables) y no se acercan a una distribución normal (tipo gaussiana), se empleó la correlación de Tau B y C de Ken- 
dall, por ser la más apropiada para este tipo de variables. Con este procedimiento se evita el problema de sobre o subestimación del verdadero valor de correlación, que se tendría con el empleo las correlaciones de Pearson y de Spearman. El Tau B se emplea cuando se correlacionan variables categóricas con el mismo número de elementos (que dan lugar a matrices cuadradas de frecuencias), mientras que el Tau $C$ es para matrices rectangulares. Este trabajo busca confirmar la consistencia de las respuestas de los entrevistados y complementa el AC.

\section{Resultados}

Los resultados de la encuesta se analizaron considerando las siguientes variables descriptivas, en categorías: perfil sociodemográfico, hábitos de viaje, intenciones de viaje pospandemia, lealtad a Colima como destino turístico y principales competidores.

\subsection{Perfil socio demográfico}

La tabla 3 presenta los resultados sobre el perfil sociodemográfico de los encuestados. Se obtuvo una respuesta relativamente homogénea por parte de ambos sexos (55-45\%); se muestra una participación relevante de profesionistas independientes y empleados frente a una proporción reducida de empresarios, con una representación moderada de jubilados, amas de casa y estudiantes.

Tanto la edad como el ingreso familiar presentan una distribución normal, con concentración de la población alrededor de la media. En el caso del ingreso, las respuestas presentan una mayor proporción de encuestados con entradas sobre la media o superiores a la media nacional (83\%) frente a aquellos que registran ingresos inferiores a esta media (17\%). En términos de edad, se advierte una mayor participación de personas de la tercera edad, frente a la de jóvenes menores de 20 años. En términos de lugar de residencia, el $94 \%$ de las respuestas fueron proporcionadas por personas residentes en el territorio nacional, con la gran mayoría radicando en el occidente y el centro del país (gráfica 1).

La gráfica 1 ilustra asimismo el hecho de que la clientela turística de Colima es esencialmente regional, con la gran mayoría proveniente de los estados vecinos de Jalisco y Michoacán, del centro del país y de la zona del Bajío, con una reducida proporción de visitantes extranjeros de los Estados Unidos de América y de Canadá. El 
resto de las respuestas se dispersan entre las diversas entidades federativas del país en forma poco representativa.

Tabla 3. Síntesis del perfil sociodemográfico de los participantes

\begin{tabular}{|c|c|c|}
\hline Variable & Indicador & Porcentaje \\
\hline \multirow{2}{*}{ Sexo } & Hombres & 55 \\
\hline & Mujeres & 45 \\
\hline \multirow{4}{*}{ Nacionalidad } & México & 93.78 \\
\hline & Estados Unidos de América & 4.44 \\
\hline & Canadá & 0.89 \\
\hline & Otros & 0.88 \\
\hline \multirow{7}{*}{ Edad } & 20 años o menos & 3 \\
\hline & $21-30$ & 22 \\
\hline & $31-40$ & 30 \\
\hline & $41-50$ & 14 \\
\hline & $51-60$ & 16 \\
\hline & $61-70$ & 11 \\
\hline & Más de 71 & 4 \\
\hline \multirow{7}{*}{ Ocupación } & Empleado & 43 \\
\hline & Profesionista independiente & 19 \\
\hline & Jubilado & 13 \\
\hline & Estudiante & 8 \\
\hline & Ama de casa & 7 \\
\hline & Empresario & 4 \\
\hline & Otras & 6 \\
\hline \multirow{3}{*}{ Ingreso familiar } & Sobre la media nacional & 27 \\
\hline & Alrededor de la media nacional & 56 \\
\hline & Por debajo de la media nacional & 17 \\
\hline
\end{tabular}

Fuente: Elaboración propia.

\subsection{Hábitos de viaje}

De acuerdo con la información obtenida mediante la encuesta, prácticamente cuatro de cada cinco encuestados manifiesta viajar con regularidad (gráfica 2). Señalaron que sus principales motivos de viaje son el descanso, la recreación y la visita a familiares y amigos, con una reducida proporción viajando por fines de negocios $u$ otros motivos, acompañados básicamente por la familia o pareja.

En su mayoría, los grupos de viaje se ubican entre una y cuatro personas, con duración de la estancia entre tres noches y una semana. Casi dos tercios del presupuesto 
de viaje de los encuestados se ubica entre los 500 y 3 mil pesos diarios, lográndose identificar, en el extremo opuesto, un segmento que manifiesta destinar 10 mil pesos diarios a sus gastos de viaje. Siete de cada 10 se trasladan a Colima en automóvil o en avión, con el $80 \%$ indicando preferencia por viajar en temporada baja.

Gráfica 1. Lugar de residencia de los encuestados

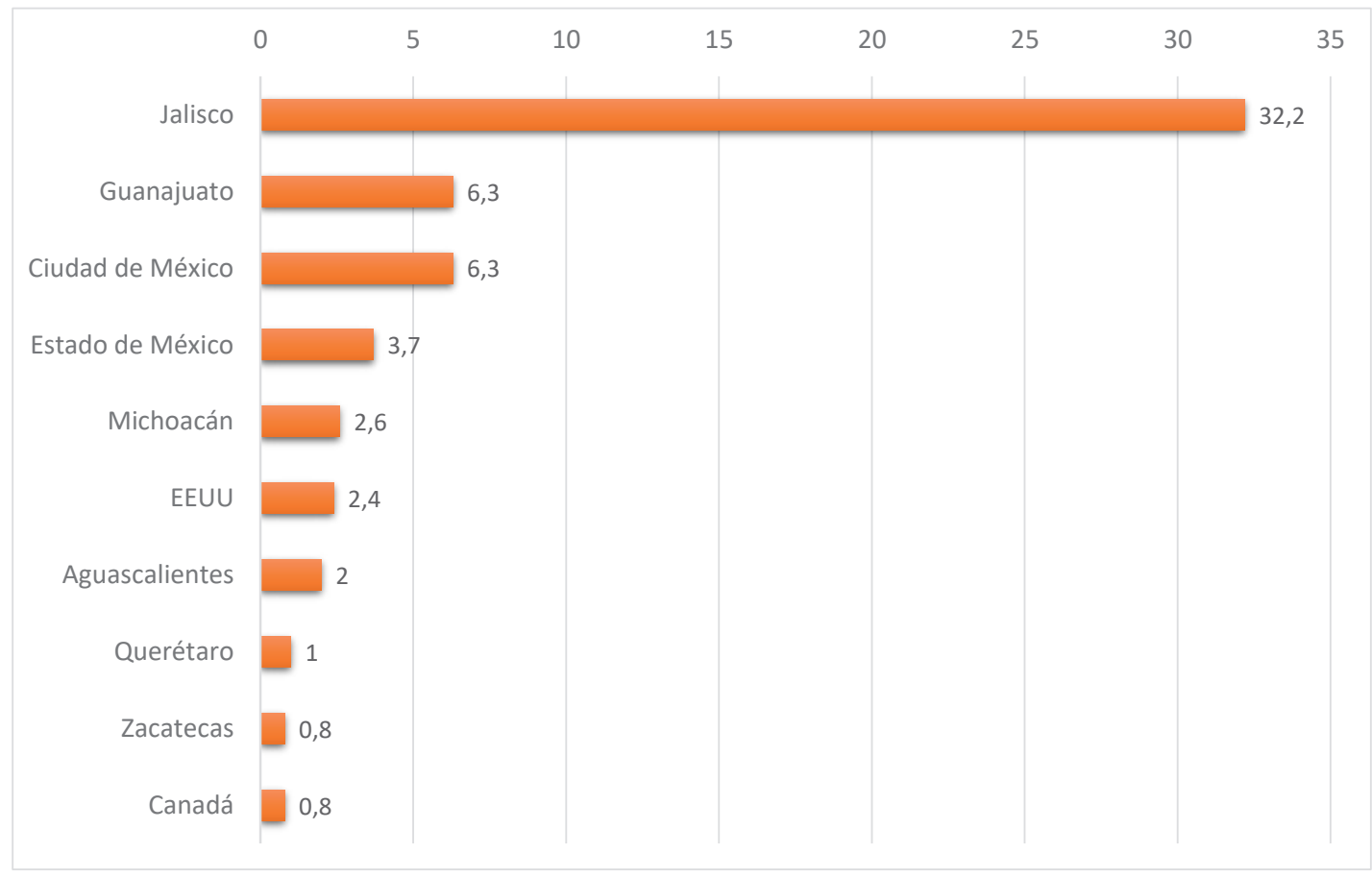

Fuente: Elaboración propia.

Gráfica 2. Viajeros regulares

¿ACOSTUMBRA VIAJAR CON REGULARIDAD?

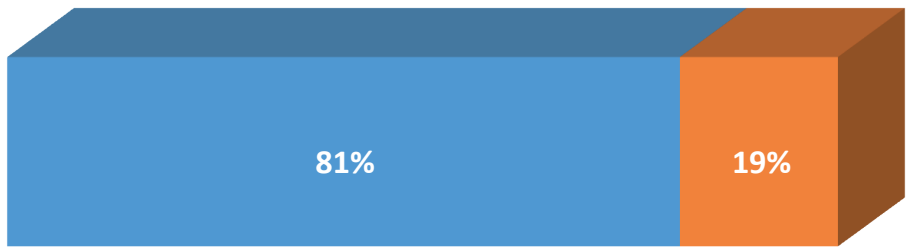

- sí $\square$ NO

Fuente: Elaboración propia. 


\subsection{Intenciones de viaje pospandemia}

Cuatro de cada cinco encuestados reveló intenciones de viajar a Colima durante el segundo semestre del 2020, tres cuartas partes con planes de hacerlo entre el verano y fin de año, mientras que el resto proyecta su viaje para el 2021. Los municipios de la entidad que captan la mayor proporción de las intenciones de viaje son Manzanillo, Colima y Comala, en ese orden.

Evidentemente, la gran mayoría quisiera rescatar sus prácticas habituales de viaje, al igual que de cualquier otro aspecto de su vida cotidiana, con una mayoría similar planeando viajar al final de la emergencia sanitaria (gráfica 3). Los resultados de la encuesta muestran que, en términos de experiencia, el interés mayor se orienta hacia atractivos de sol y playa, pueblo mágico y naturaleza, con una amplia dispersión hacia otras modalidades turísticas. Las formas de hospedaje seleccionadas por los encuestados son los hoteles todo incluido y los hoteles de tres y cuatro estrellas, cubriendo poco más del $50 \%$ de las preferencias, seguidos por el emergente Airbnb y la estancia con familiares y amigos.

Casi la totalidad espera que los prestadores de servicios turísticos apliquen medidas sanitarias, como el desarrollo de protocolos de seguridad, algún tipo de certificación que demuestre que el establecimiento se encuentra libre de COVID-19, y procedimientos especiales de desinfección (gráfica 4). En general, de las respuestas obtenidas mediante esta pregunta puede inferirse que es deseable la implementación de algún tipo de medida de asepsia que disminuya las probabilidades de contraer enfermedades contagiosas. En ese mismo sentido, seis de cada diez encuestados tienen la expectativa de que los establecimientos turísticos enfaticen las acciones de higiene y limpieza, mientras que una quinta parte espera mayor responsabilidad y solidaridad (gráfica 5).

Gráfica 3. Planes de los encuestados para viajar al final de la emergencia sanitaria

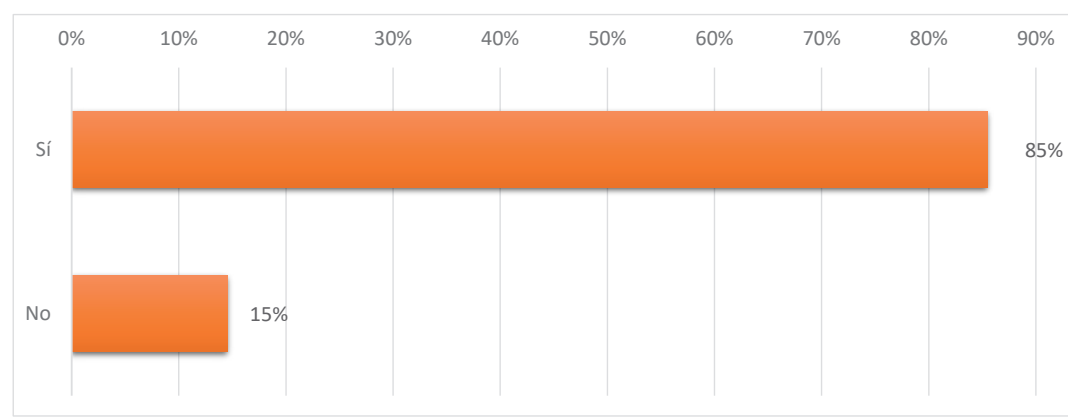

Fuente: Elaboración propia. 


\section{Gráfica 4. Medidas preventivas en empresas turísticas, esperadas por los encuestados}

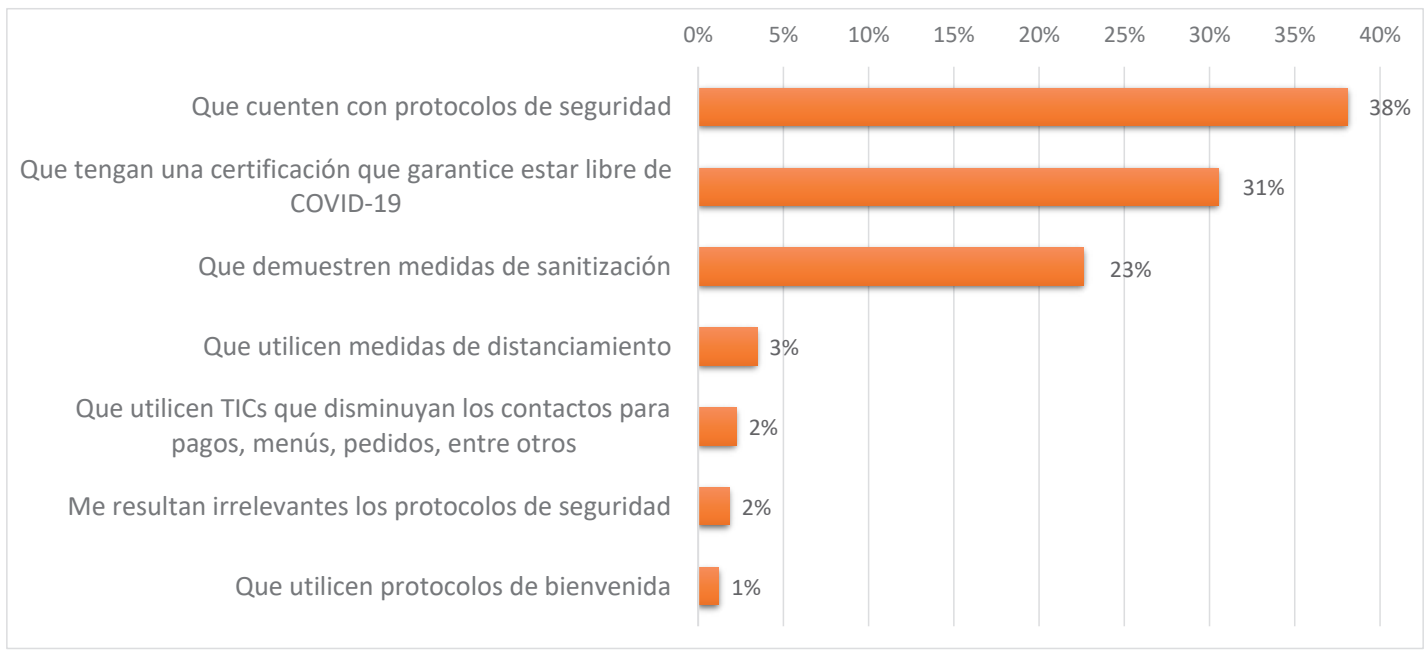

Fuente: Elaboración propia.

\section{Gráfica 5. Expectativas de cambios en la cultura de viaje}

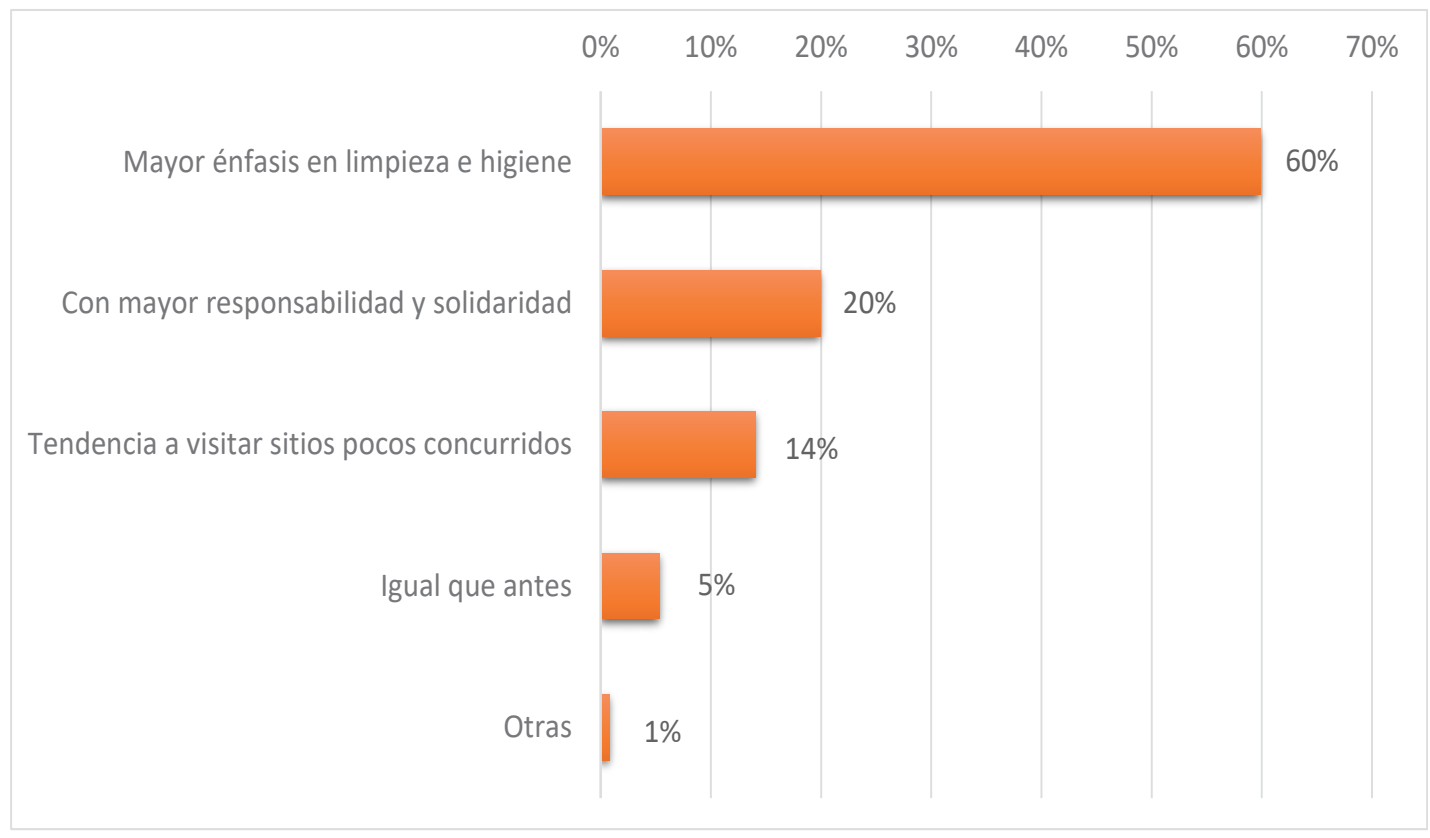

Fuente: Elaboración propia. 
Entre los motivos que los impulsarían a seguir viajando se mencionan: el gusto por hacerlo, seguir con sus planes vacacionales y visitar familiares y amigos, así como la necesidad de relajarse y liberarse del estrés (gráfica 6). Llama la atención que, además del temor a contagios, la situación económica se presenta como el segundo motivo que les impediría viajar (gráfica 7).

Gráfica 6. Motivos manifestados por los encuestados para continuar viajando

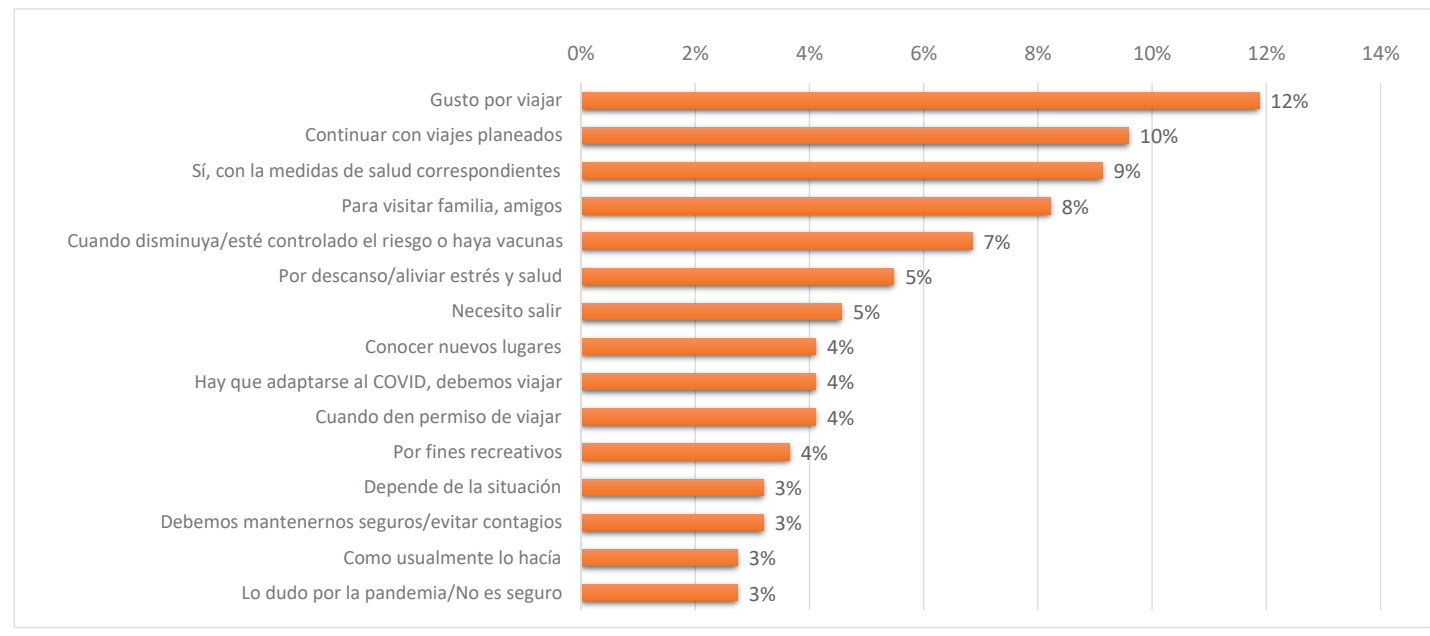

Fuente: Elaboración propia.

\subsection{Lealtad a Colima como destino turístico}

Cuatro de cada cinco encuestados ha visitado el estado de Colima en alguna ocasión; prácticamente dos de cada tres han repetido visita y poco menos de la mitad pueden considerarse visitantes leales o asiduos, con cerca de cinco viajes al destino, lo cual puede considerarse una ventaja competitiva sustancial (gráfica 7).

A la par de proporcionar la mayor parte de sus visitantes, Jalisco se presenta como el principal competidor turístico de la entidad, especialmente en la zona de la Bahía de Banderas. El estado de Quintana Roo y el puerto de Mazatlán aparecen seguidamente, como destinos a los que los encuestados viajarían en caso de no decidirse por Colima (gráfica 8). 
Gráfica 7. Frecuencia con que los encuestados han visitado Colima con anterioridad

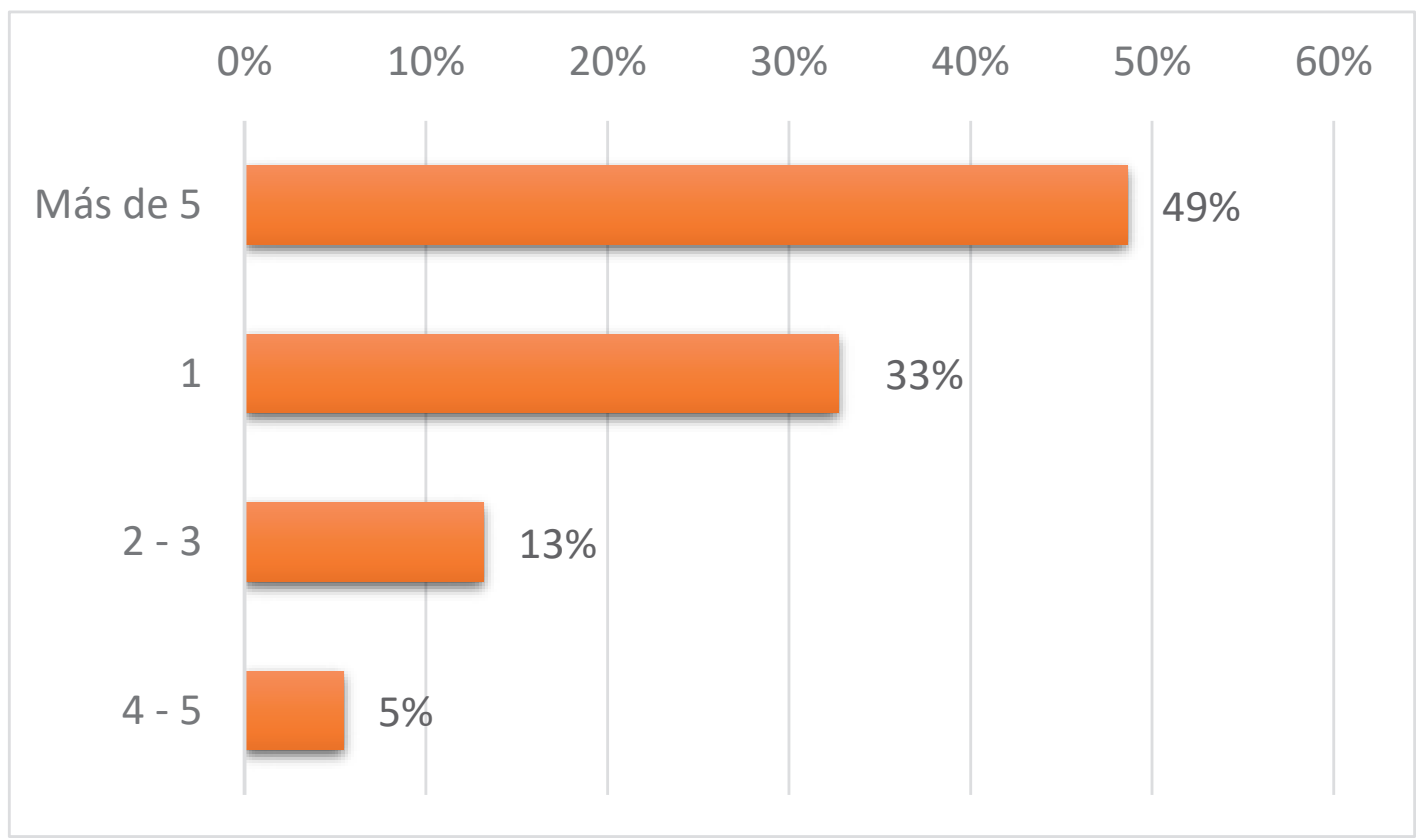

Fuente: Elaboración propia.

Gráfica 8. Destinos que los encuestados visitarían en caso de no viajar a Colima

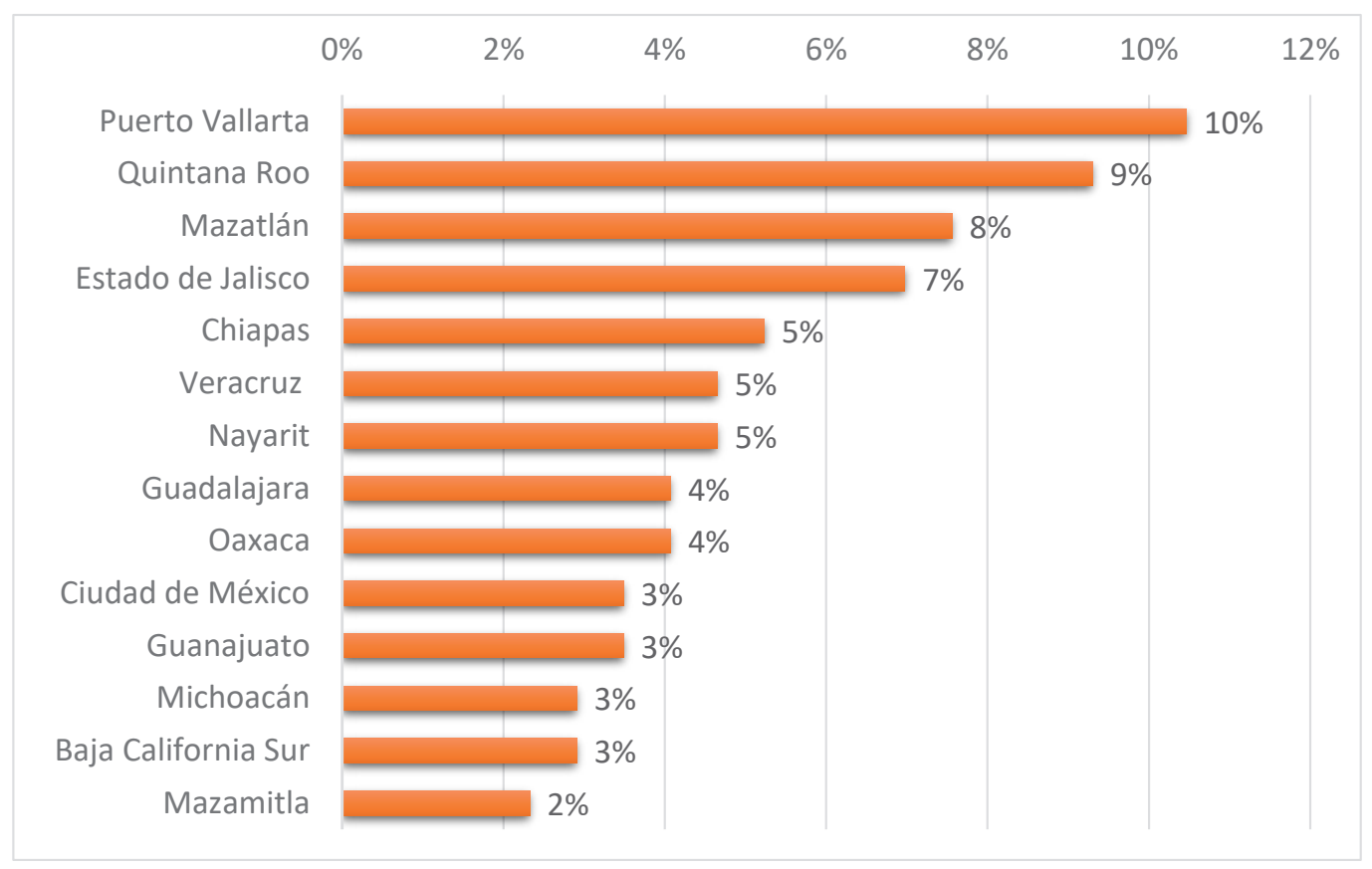

Fuente: Elaboración propia. 


\subsection{Análisis de correspondencias sobre las intenciones de viaje pospandemia}

La tabla 4 muestra la matriz de cruce de variables categóricas ${ }^{1}$, donde los asteriscos indican que el estadístico de rechaza a $\mathrm{HO}$; esto es, se puede afirmar que existe relación entre las variables cuando se presenta una confiabilidad mayor a 90\%. En el caso de la presente encuesta, de un total de 108 cruces de variables categóricas, 49 resultaron significativas, el $45.4 \%$ de los casos.

Tabla 4. Resumen de asociación de variables en análisis de correspondencia

\begin{tabular}{|c|c|c|c|c|c|c|}
\hline Variables & $\begin{array}{l}\text { Lugar de } \\
\text { residencia } \\
1 /\end{array}$ & $\begin{array}{c}\text { Ocupación } \\
\text { agregada } \\
1 /\end{array}$ & $\begin{array}{c}\text { Grupos } \\
\text { de edad } \\
1 /\end{array}$ & $\begin{array}{l}\text { Compañía } \\
\text { de viaje 1/ }\end{array}$ & $\begin{array}{l}\text { Tamaño de } \\
\text { su grupo } \\
\text { de viaje 1/ }\end{array}$ & $\begin{array}{l}\text { El ingreso } \\
\text { de su familia } \\
\text { se ubica } 1 /\end{array}$ \\
\hline Motivos de viaje & $* *(0.053)$ & $* *(0.053)$ & $* *(0.09)$ & & & \\
\hline Compañía de viaje $1 /$ & $* * *(0.065)$ & & $* * *(0.227)$ & & & \\
\hline $\begin{array}{l}\text { Tamaño de su grupo } \\
\text { de viaje } 1 /\end{array}$ & $*(0.042)$ & $* * *(0.09)$ & $* * *(0.132)$ & $* * *(0.627)$ & & \\
\hline $\begin{array}{l}\text { Duración promedio } \\
\text { de sus viajes }\end{array}$ & $* * *(0.105)$ & $* *(0.053)$ & $*(0.114)$ & $* *(0.095)$ & $* *(0.092)$ & $* * *(0.061)$ \\
\hline $\begin{array}{l}\text { Presupuesto normal } \\
\text { por día de viaje }\end{array}$ & & $* * *(0.167)$ & $* * *(0.238)$ & $* * *(0.141)$ & & $* * *(0.099)$ \\
\hline Modo de transporte & $* * *(0.112)$ & $* *(0.059)$ & $* *(0.06)$ & $* * *(0.125)$ & $* * *(0.136)$ & $* * *(0.037)$ \\
\hline $\begin{array}{l}\text { El ingreso de su familia } \\
\text { se ubica } 1 /\end{array}$ & & & & & $* * *(0.049)$ & \\
\hline $\begin{array}{l}\text { Cuando usted viaja, } \\
\text { su forma de pago es }\end{array}$ & & $* * *(0.14)$ & $* * *(0.138)$ & & & $* * *(0.042)$ \\
\hline $\begin{array}{l}\text { Cuándo planea realizar } \\
\text { su próximo viaje }\end{array}$ & & & & $* *(0.071)$ & & \\
\hline $\begin{array}{l}\text { Prefiere viajar } \\
\text { en temporada }\end{array}$ & $* *(0.03)$ & $* * *(0.072)$ & $* * *(0.07)$ & $* *(0.032)$ & & \\
\hline $\begin{array}{l}\text { Concluida la emergencia } \\
\text { sanitaria, ¿qué } \\
\text { experiencia buscará } \\
\text { en su próximo viaje? }\end{array}$ & $* *(0.053)$ & & $* * *(0.115)$ & $* *(0.07)$ & & \\
\hline $\begin{array}{l}\text { Concluida la emergencia } \\
\text { sanitaria, ¿qué tipo } \\
\text { de hospedaje buscará } \\
\text { en próximo viaje? }\end{array}$ & $*(0.042)$ & $* * *(0.077)$ & $* * *(0.098)$ & & & \\
\hline $\begin{array}{l}\text { ¿Qué medidas } \\
\text { preventivas sanitarias } \\
\text { espera de } \\
\text { establecimientos } \\
\text { turísticos? }\end{array}$ & & & $* *(0.106)$ & & & \\
\hline
\end{tabular}

\footnotetext{
1 Las variables categóricas pueden considerarse cualitativas; por ejemplo, hombre-mujer; lugar de residencia: Jalisco, Guanajuato, etcétera; grupo de edad: 21 a 30 años, 31 a 40 años, 41 a 50. Se contraponen a las variables cuantitativas o continuas.
} 
Continuación de la tabla 4

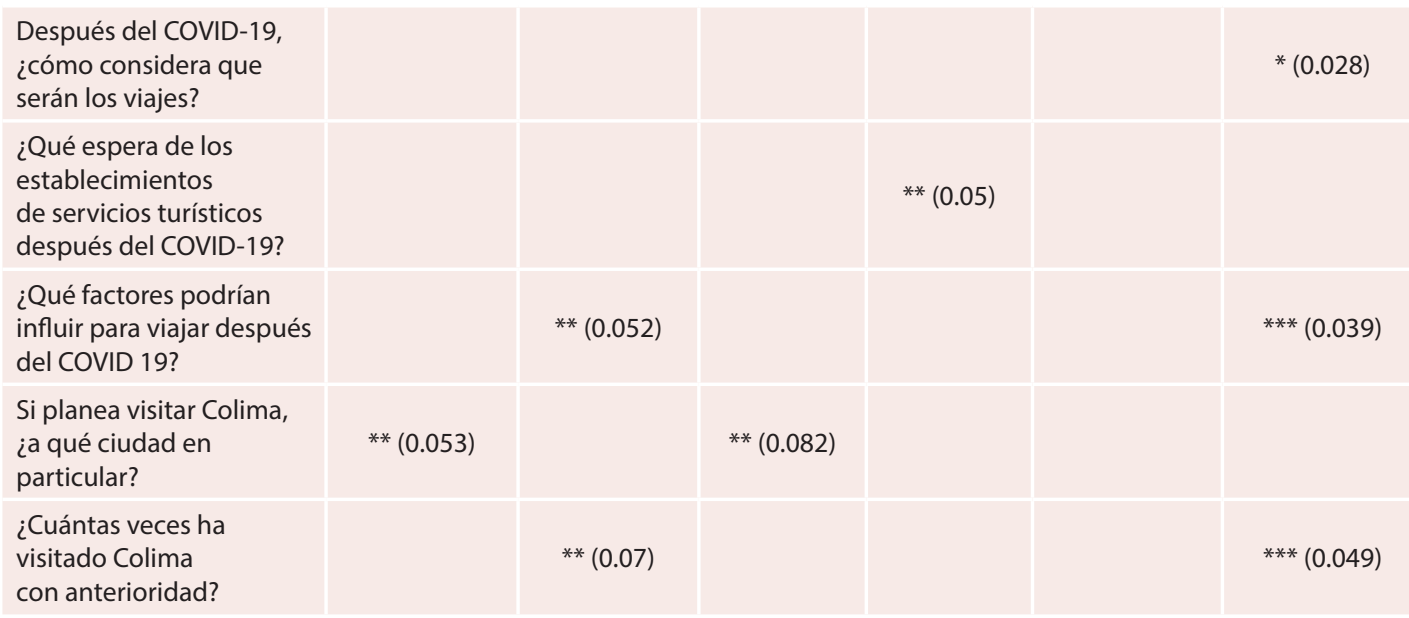

Notas: Significancia estadística: ${ }^{* *}=99 \%,{ }^{* *}=95 \%$ y $=90 \% .1 /$ Indica que es una variable socioeconómica.

Los números entre paréntesis son los valores de inercia total.

Fuente: Elaboración propia.

\subsubsection{Lugar de residencia e intenciones de viaje}

Las principales relaciones de correspondencia en cuanto a lugar de residencia se encontraron entre la región occidental y el centro del país. Las personas que provienen del occidente del país (Jalisco, Michoacán, Zacatecas y Aguascalientes) buscan básicamente recreación y descanso por periodos cortos de tiempo (fin de semana, puentes o una a dos noches), con marcada preferencia por actividades de sol y playa o la ciudad de Colima. Generalmente se acompañan de familiares y amigos en grupos de tres a seis personas. Viajan principalmente por automóvil o autobús, en temporada baja y hospedándose básicamente en hoteles. Las personas que provienen del Centro del país (Ciudad de México, Estado de México o Guanajuato) viajan en autobús, en grupos de más de ocho personas, permanecen por una semana y buscan quedarse en Manzanillo, alojándose en hostales o cabañas (tabla 4).

\subsubsection{Ocupación agregada e intenciones de viaje}

Los empresarios tienen la motivación de viajar por negocios, se movilizan en automóvil en grupos de tres a cuatro personas y permanecen en su destino turístico por tres o cuatro noches, gastando entre 5 a 10 mil pesos por día y pagan sus gastos empleando tarjetas o efectivo. Son el grupo con mayor frecuencia de visita, pues han estado más de cinco veces en la entidad. Consideran que se hospedarán en hostal o 
cabaña después del COVID-19 y comentan que factores como los contagios influirán en sus viajes posteriores a la pandemia (tabla 4).

Los empleados y profesionistas independientes presentan patrones similares de intenciones de viaje. Sus motivos son recreación y descanso; viajan en pareja o grupos de tres a cuatro personas, permaneciendo una o dos noches, fines de semana y ocasionalmente cinco o seis noches. Viajan por automóvil y/o en avión, pagan con tarjeta de crédito con gastos entre 2 a 2 mil 500 pesos por día. Eligen viajar en temporada baja y alojarse en hoteles, habiendo visitado Colima en tres, cuatro o cinco ocasiones previas. Más que la pandemia, consideran que el factor ingresos registrará la mayor influencia en sus viajes después del COVID-19 (tabla 4).

El principal motivo de viajes de los estudiantes es la visita a familiares y amigos, se desplazan por autobús en grupos de cinco a seis personas, permaneciendo en el destino por dos semanas y reservando su alojamiento a través de la plataforma Airbnb. Viajan en periodo vacacional, con gastos de 500 a mil pesos al día, que pagan principalmente en efectivo. Han visitado Colima al menos una vez anteriormente y consideran que factores como los contagios influirán en sus viajes después del COVID-19. Otros grupos como los jubilados viajan para visitar familiares y amigos. Las amas de casa han visitado Colima en repetidas ocasiones, de cuatro a cinco veces y gastan de 500 a mil pesos al día (tabla 4).

\subsubsection{Grupos de edad e intenciones de viaje}

Grupos de jóvenes: los adolescentes (menos de 20 años) viajan en grupos de cinco a seis personas y gastan entre mil 500 a 2 mil pesos por día y presentan extremos en la duración de su estancia: permanecen dos semanas o más, o viajan de ida y vuelta. Los jóvenes de 21 a 30 años viajan los fines de semana o en puentes, se movilizan por autobús, prefieren visitar la ciudad de Colima a la costa, gastando de 3 a 3 mil 500 pesos diarios; reservan mediante Airbnb y tienen la expectativa de que los establecimientos turísticos presenten medidas preventivas sanitarias y de distanciamiento social. Los grupos de jóvenes generalmente pagan en efectivo y prefieren salir en temporadas vacacionales.

Grupos en edad de trabajar: a las personas de 31 a 40 años les motivan los viajes por recreación o descanso, viajan solos o en grupos grandes (siete a ocho personas), permanecen en el destino una semana, buscan destinos de sol y playa, y tienen gastos de 2 mil 500 a 3 mil por día. Su hospedaje de elección son hoteles, hostales 
o cabañas. El grupo de 41 a 50 años viaja en familia en grupos de tres a cuatro personas, con motivos de recreación y descanso. Se movilizan por automóvil, en temporada baja en destinos en la modalidad sol y playa, gastando más de 10 mil pesos al día, hospedándose en hoteles, hostales o cabañas. El grupo de 51 a 60 años tiene motivos diversos para viajar, permanecen en su destino por dos semanas o más, prefieren temporadas bajas, pagan con tarjeta de crédito y visitan ciudades como Colima y Comala.

Grupos de la tercera edad: a las personas de más de 70 años los motivan aspectos como la salud; viajan en pareja o con amistades, se movilizan por avión, pagan con tarjeta de débito y sus gastos se ubican entre mil a mil 500 pesos al día. Los de 60 o más años buscan preferentemente destinos de sol y playa, manifestando preocupación por la inseguridad (tabla 4).

\subsubsection{Compañía e intenciones de viaje}

Los encuestados que viajan en pareja se trasladan por avión, con estancias de dos a cuatro noches, gastando de 5 a 10 mil en temporada baja. Tienen expectativas de que los establecimientos turísticos presenten certificaciones contra COVID-19. Si viajan exclusivamente en familia, los grupos son de tres a cuatro personas, por periodos de una semana, con gastos de 2 mil 500 a 3 mil pesos al día y se movilizan por automóvil; estos grupos familiares esperan visitar ciudades en semana santa o verano del 2021. Si además de la familia se movilizan con amigos, los grupos aumentan de cinco a ocho personas o más, se desplazan por autobús, en periodos vacacionales, con destinos diversos como sol y playa, pueblos mágicos y atracciones rurales. Esperan que los establecimientos turísticos cuenten con protocolos de seguridad y menor aglomeración (tabla 4).

\subsubsection{Tamaño del grupo e intenciones de viaje}

Los grupos de uno a dos personas prefieren viajar durante puentes, se trasladan en avión y su nivel de ingreso es similar a la media nacional. El grupo de tres a cuatro personas permanece en su destino turístico de tres a cuatro noches, se trasladan por automóvil, y su nivel de ingreso familiar se ubica por arriba de la media. Esta variable fue la que menos cruces significativos presentó con el resto de opciones de intenciones de viaje (tabla 4). 


\subsubsection{Ingreso familiar e intenciones de viaje}

Las familias con ingresos por encima de la media nacional permanecen por tres o cuatro noches en sus destinos turísticos, se movilizan por avión, pagan con tarjeta de crédito y sus gastos se ubican entre 5 y 10 mil pesos diarios; son la clientela más leal a Colima, con al menos cinco visitas previas. Entre sus expectativas enfatizan su preocupación por la limpieza e higiene, y la inseguridad.

Las familias con ingresos alrededor de la media permanecen en sus destinos una o dos noches, se movilizan por automóvil y liquidan sus gastos, ubicados en rangos de mil a mil 500 o de 4 a 5 mil pesos diarios con tarjeta de crédito. Sus expectativas para los viajes posteriores a la pandemia de COVID-19 se refieren a responsabilidad y solidaridad, manifestando preocupaciones por el riesgo de contagio. Las familias con ingresos por debajo de la media se mueven en autobús, tienen viajes cortos (de ida y vuelta), gastando de 500 a mil pesos al día. Después del COVID-19 esperan visitar sitios poco concurridos (tabla 4).

\subsubsection{Correlaciones bivariadas}

La tabla 5 presenta las correlaciones Tau B y C de Kendall. Como se observa, los valores en cada caso son similares, así como su nivel de significancia. Destaca que de 21 correlaciones bivariadas, 11 son significativas (52.3\%). A manera de ejemplo, los resultados de la encuesta muestran que, si el grupo de viaje aumenta de edad, disminuye el tamaño del grupo y la duración promedio, incrementando el importe de su gasto, el número de visitas a Colima y su ingreso familiar.

Evidentemente, el incremento en el tamaño del grupo aumenta el presupuesto para el gasto del viaje. Si el ingreso familiar crece, asciende asimismo la inversión por día, el número de visitas a Colima y se adelantan las fechas programadas para viajar. Debe mencionarse, sin embargo, que las correlaciones establecidas no son muy significativas, por lo que su poder de predicción es limitado; en ciencias sociales, 0.4 es un valor de correlación aceptable (Salvador-Figueras, 2003). 
Tabla 5. Correlaciones bivariadas de variables de perfil sociodemográfico y hábitos de viaje

\begin{tabular}{|c|c|c|c|c|c|c|c|}
\hline Variables categóricas & GE & TGV & DPV & PND & IF & PPV & VCA \\
\hline Grupos de edad (GE) & 1 & $-.093^{*}$ & $-.083^{*}$ & $.150^{* *}$ & $.129 * *$ & & $.074^{*}$ \\
\hline Tamaño de su grupo de viaje (TGV) & $-.084^{*}$ & 1 & & $.086^{*}$ & & & \\
\hline Duración promedio de viajes (DPV) & $-.079 *$ & & 1 & & & & \\
\hline Presupuesto normal por día de viaje (PND) & $.147^{* * *}$ & $0.081^{*}$ & & 1 & $.186^{* *}$ & $-.074^{*}$ & \\
\hline El ingreso de su familia se ubica (IF) & $.128^{* * *}$ & & & $.195^{* * *}$ & 1 & $-.128^{* *}$ & $.144^{* *}$ \\
\hline Cuándo planea realizar su próximo viaje (PPV) & & & & $-.074^{*}$ & $-.127^{* * *}$ & 1 & $-.172^{* *}$ \\
\hline Veces ha visitado Colima con anterioridad (VCA) & $.069^{*}$ & & & & $.134^{* * *}$ & $-.159 * * *$ & 1 \\
\hline
\end{tabular}

Notas: Valores de la correlación Tau-B de Kendall se encuentran en la esquina superior derecha de la diagonal principal; $y$ los de Tau-C de Kendall en la parte inferior izquierda. Significancia estadística: ${ }^{* *}=99 \%,{ }^{* *}=95 \%$ y $=90 \%$.

Fuente: Elaboración propia.

\section{Discusión}

La situación que se enfrenta actualmente desde ningún punto de vista puede considerarse sencilla. A la pandemia se agregan la crisis económica y el contexto de inseguridad en el territorio nacional, que ha afectado especialmente la recepción de turistas estadounidenses en la entidad. EI COVID-19 ha generado una parálisis social que suprime las intenciones de viajar de las personas y, aunque lo desearan, el contexto económico ha privado a parte importante de la sociedad de sus actividades, consecuentemente, de su empleo y su ingreso.

De la información recabada durante la investigación y considerando la situación actual de la pandemia, puede esperarse que el escenario se prolongue por lo menos hasta el final del presente año. Se sabe de esfuerzos significativos de instituciones y laboratorios por desarrollar vacunas y medicamentos, aunque no estarán disponibles en el futuro inmediato; también se ha mencionado una disminución de la agresividad del virus, aunque por el momento esto no constituye ninguna garantía. Los registros históricos sobre crisis y pandemias muestran que después de caídas considerables en la actividad turística se presenta una recuperación que eventualmente será superada.

Los datos de la encuesta demuestran que las personas desean continuar con sus prácticas tradicionales de viaje, aunque no resulte viable en el corto plazo. Esto es, en términos de demanda permanece el deseo de trasladarse, aunque las restricciones impuestas por la pandemia no lo permitan. Asimismo, estos datos son relevantes respecto al perfil sociodemográfico y los hábitos de viaje de los consumidores 
de Colima como destino turístico, que pueden utilizarse para fines de desarrollo de producto y comercialización.

Colima cuenta con una clientela turística regional, con viajeros de corta distancia, pertenecientes mayoritariamente a clases alta y media alta o, en términos de la Asociación Mexicana de Agencias de Inteligencia de Mercado y Opinión Pública (AMAI, 2020), a los niveles socioeconómicos $A, B$ y $C$, con hábitos de viaje tradicionales en cuanto a motivos y modalidades de hospedaje, orientados al disfrute de playas y a visitar familiares y amigos; desde el punto de vista de la segmentación, la mercadotecnia turística de Colima parece encontrarse bien enfocada, de acuerdo con los planteamientos de Svensson et al. (2011). Esta clientela tradicional quisiera recuperar sus hábitos de viaje acostumbrados y, frente a la situación epidemiológica, esperaría un conjunto de medidas preventivas de higiene y desinfección.

Entre los resultados obtenidos destaca que, además de las precauciones sanitarias, los futuros visitantes muestran cautela frente a las perspectivas económicas y la inseguridad, que se ha convertido en un riesgo permanente en todo el país. Las respuestas también demuestran que las vacaciones y los viajes no son considerados un bien de lujo o suntuario, sino que son percibidos como actividades normales que responden a la necesidad de descansar, recuperarse y convivir con la familia, habiendo desarrollado un conjunto de hábitos de viaje (Zieba, 2017).

Se demostró que Colima continúa siendo un destino turístico regional, no se diga nacional o internacional; en términos de competitividad turística, la entidad no puede considerarse un rival frente a sus principales competidores en los indicadores básicos relativos a cantidad de visitantes, captación de turistas internacionales, número de habitaciones y tasa de ocupación hotelera (Vu y Turner, 2011; Croes, 2011; Mazanec y Ring, 2011; Ivars et al., 2013; Dupeyras y MacCallum, 2013). Sin embargo, el estado sí es competitivo en un indicador de relevancia fundamental para la mercadotecnia de los destinos turísticos: la lealtad, aunada a las intenciones conductuales positivas y el apego al destino turístico (Pike, 2012; Chen y Phou, 2013; Caber et al., 2012).

El AC demostró que entre los clientes leales se encuentran segmentos con elevada capacidad de consumo. La información de la encuesta muestra que Colima compite con destacados destinos turísticos de nivel internacional como son los estados de Quintana Roo y Jalisco y con regiones como la Bahía de Banderas y la Riviera Nayarit. 
En el campo del AC, las correlaciones más significativas identificadas en las variables analizadas se refieren a aspectos geográficos (lugar de residencia), ocupación, grupos de edad, compañía de viaje e ingreso familiar, presentando un nivel de significancia estadística de $99 \%$. En este mismo nivel, sobresalen los indicadores relativos al tamaño del grupo de viaje, presupuesto diario, medio de transporte y forma de pago. Adicionalmente, se logró determinar otro conjunto de 19 variables e indicadores presentando relaciones con nivel de significancia de $95 \%$ y un tercer conglomerado de cuatro correlaciones al 90\% (tabla 3). En términos de correlaciones Tau B y C de Kendall, se localizaron 11 correlaciones significativas (52.3\%), aunque con capacidad de predicción reducida (Salvador-Figueras, 2003; Aldás y Uriel, 2017) (tabla 4).

Los resultados del AC pueden ser empleados por los encargados de la mercadotecnia turística del estado de Colima para diseñar paquetes y ofertas específicas, dirigidas a los diversos segmentos de mercado identificados mediante el estudio. Como señalan Dolnicar et al. (2018), la apropiada identificación de los segmentos de mercado en cuanto a la clientela potencial de un destino turístico aporta un conjunto de beneficios. Entre otros, permite seleccionar aquellos que resultan más rentables y convenientes; de la misma manera, posibilita la adecuación de la oferta de servicios a sus gustos y preferencias, así como la identificación de los canales de comunicación apropiados para transmitirlas.

La adecuada segmentación de la clientela potencial de un destino turístico proporciona ventajas competitivas de largo plazo, contribuyendo a fortalecer su posicionamiento y a enfocar los esfuerzos de comercialización en los clientes apropiados para el destino (Camilleri, 2018).

\section{Conclusiones}

El sector de los viajes y el turismo ha sido uno de las más afectados por el COVID-19, al tiempo que fue el vehículo mediante el que la enfermedad viral llegó a convertirse en pandemia, hasta casi paralizar la economía mundial, registrándose más de 16 millones de personas contagiadas y cerca de 650 mil decesos en el planeta.

Si bien el turismo ha sido tradicionalmente considerado como una industria superflua, frívola o suplementaria, genera el $10 \%$ del PIB y los empleos en el mundo (Organización Mundial del Turismo, 2019). La paralización a consecuencia de la 
pandemia ha hecho brillar por su ausencia a este sector por la notoria cantidad de empleos, ingresos e impuestos que genera, así como por el efecto multiplicador que registra en el contexto socioeconómico general.

Este trabajo se centró en obtener información sobre perspectivas de viaje a Colima para la etapa pospandemia, respaldada con fuentes académicas y estadísticas confiables. El estudio empírico permitió conseguir elementos sobre el perfil sociodemográfico y los hábitos de viaje de la clientela turística de la entidad. De igual manera, se obtuvieron datos sobre impactos de crisis económicas y pandemias ocurridas en el pasado reciente. Igualmente se consideraron temas académicos relacionados con la gestión de destinos turísticos y, dentro de este campo, la gestión de crisis y desastres.

De acuerdo con la investigación realizada y con el fin de superar la crisis actual, uno de los objetivos primordiales será establecer las bases dirigidas a iniciar una nueva ruta para el turismo en la entidad, centrándose en el impulso a la sustentabilidad y el desarrollo incluyente, fortaleciendo la planta productiva y la oferta de servicios turísticos, reforzando a pequeñas y medianas empresas turísticas y a prestadores de servicios independientes, con el propósito de reactivar la captación de turistas, la derrama económica y la conservación de empleos en el sector.

\section{Implicaciones para la gestión del destino turístico Colima}

Los resultados obtenidos permiten formular un conjunto de implicaciones para la gestión del destino Colima, que pueden aplicarse a mejorarla, presentando las siguientes recomendaciones:

- Uno de los principios básicos para alcanzar la competitividad de los destinos turísticos propuestos por Ritchie y Crouch (2005), es el fortalecimiento de la coopetencia esto es, la cooperación entre empresas al interior de la industria turística colimense que compiten entre sí; aunque rivalicen se recomienda el establecimiento de alianzas para competir con los destinos turísticos rivales de la entidad. La existencia de tres organismos representantes de hoteles en este pequeño estado ilustra la falta de cohesión entre los operadores turísticos locales.

- Formular planes conjuntos de largo plazo que impulsen la competitividad del destino Colima, incluyendo aspectos como el desarrollo de atractivos turísticos, 
formación de personal, introducción de tecnologías de información y comunicación, fortalecimiento de la seguridad, gestión de financiamiento y, por supuesto, formular planes de contingencia para enfrentar crisis y desastres, especialmente considerando la cuestión territorial, donde se han presentado ciclones, terremotos, maremotos, erupciones volcánicas y accidentes catastróficos.

- Impulsar la adopción de mecanismos de comercialización más allá de las acciones tradicionales de promoción, como la mercadotecnia digital y la mejora de la experiencia de visita en el destino; esto es, complementar las acciones de "empujar" (promoción) con medidas para "jalar" (mejora de la experiencia de visita) a los consumidores con base en estudios de comportamiento.

- Formular estrategias de largo plazo que permitan a Colima superar su condición de destino turístico regional, al tiempo que, en el corto plazo, se desarrollen planes de comercialización tendientes a profundizar su cobertura.

- Desarrollar acciones conjuntas entre organizaciones turísticas que impulsen la adopción de medidas de seguridad, higiene, certificaciones y acciones de desinfección en general, que posicionen a Colima como un destino turístico responsable y seguro, generando un sello distintivo que influya positivamente en la percepción del turista. Además de impulsar estas medidas en forma generalizada en el destino, es necesario darlas a conocer a través de diversos medios de comunicación y redes sociales.

- Promover investigaciones de mercado a profundidad, enfocadas en el comportamiento del consumidor y explorando con mayor detalle las relaciones esbozadas en el AC desarrollado en el presente estudio, a fin de aplicar estrategias de mercadotecnia de precisión dirigidas a los diversos nichos y segmentos de turistas de la región.

Como sugieren Sheldon y Dwyer (2010), los líderes públicos y privados del sector pueden aprovechar la actual crisis y la ralentización de la industria turística para reflexionar sobre las perspectivas de desarrollo del turismo en el largo plazo, en términos de sus impactos sociales y ambientales, así como para formular planes para su restructuración, en función de los cambios económicos y sociodemográficos. De la misma manera, la gravedad de la situación generada por la actual pandemia lleva a ponderar la necesidad de formular planes para la gestión de crisis y desastres que en algún futuro se presentarán, con toda seguridad. 


\section{Limitaciones del trabajo}

Entre las limitaciones del presente trabajo puede mencionarse la necesidad de agrupar ciertos indicadores para la creación de variables categóricas, realizando, en algunas ocasiones, agrupamientos convenientes o basados en la experiencia del investigador y no con base en modelos teóricos tradicionales, ya que los agrupamientos pueden modificar la significancia estadística del cruce de las variables categóricas o de la cercanía de sus elementos. Esta limitación puede justificarse explicando que el trabajo se realizó en un plazo reducido, ante la urgencia de entregar el reporte a la brevedad posible.

Por otra parte, el análisis de correspondencia realizado no puede considerarse un procedimiento de segmentación del mercado concluido; la identificación de las correlaciones encontradas representa una etapa preliminar en un procedimiento de segmentación, por lo cual una propuesta para futuras investigaciones sería realizar dicho procedimiento de manera ampliada, rescatando la información y la experiencia obtenidas en el presente trabajo.

\section{Referencias}

Aldás J. y Uriel, E. (2017). Análisis multivariante aplicado con R. Editorial Paraninfo.

Asociación Mexicana de Agencias de Inteligencia de Mercado y Opinión Pública (AMAI). (2020). ¿Cuántos niveles socioeconómicos hay y cuáles son sus principales características? https://bit.ly/2GH2P8p

Barros, C. y Machado, L. (2010). The length of stay in tourism. Annals of Tourism Research, 37(3), 692-706. https://doi.org/10.1016/j.annals.2009.12.005

Bunghez, C. (2016). The importance of tourism to a destination's economy. Journal of Eastern Europe Research in Business \& Economics, 1-9. https://doi. org/10.5171/2016.143495

Caber, M., Albayrak, T. y Matzler, K. (2012). Classification of the destination attributes in the content of competitiveness (by revised importance-performance analysis). Journal of Vacation Marketing, 18(1), 43-56. https://doi. org/10.1177/1356766711428802 
Camilleri, M. (2018). Market segmentation, targeting and positioning. En Travel marketing, tourism economics and the airline product (pp. 69-83). Springer.

Cázares, E. (2020, 5 de agosto). Durante agosto disminuirán vuelos de Manzanillo a Ciudad de México. AF Medios. https://bit.ly/3byR2Ec

Chen, C. F. y Chen, F. S. (2010). Experience quality, perceived value, satisfaction and behavioral intentions for heritage tourists. Tourism Management, 31(1), 2935. https://doi.org/10.1016/j.tourman.2009.02.008

Chen, C. y Phou, S. (2013). A closer look at destination: image, personality, relationship and loyalty. Tourism Management, 36, 269-278. https://doi.org/10.1016/j. tourman.2012.11.015

Consejo Nacional Empresarial Turístico (CNET). (2020). Estimación de las afectaciones al turismo mexicano en 2020 como consecuencia de la pandemia del COVID-19, Documento 14 [cuaderno de trabajo]. http://bitly.ws/9CTV

Croes, R. (2011). Measuring and explaining competitiveness in the context of smaII island destinations. Journal of Travel Research, 50(4), 431-442. https://doi. org/10.1177/0047287510368139

Datatur. (2020). Turismo en México 2020. Secretaría de Turismo. https://datatur.sectur.gob.mx/Documentos Publicaciones/turmx2009.pdf.

Oficina de Asuntos Consulares. (2020) Mexico travel advisory. https://bit.ly/2ZfuFPw

Dolnicar, S., Grün, B. y Leisch, F. (2018). Market segmentation analysis: Understanding it, doing it, and making it useful. Springer Nature.

Dupeyras, A. y MacCallum, N. (2013). Indicators for measuring competitiveness in tourism: A guidance document. OECD Tourism Papers. http://doi.org/10.1787/5k47t9q2t923-en

El Comentario (2020, 1 de junio). Un 12\% de los restaurantes del estado ya no pudieron abrir este 1 de junio: Canirac. http://bitly.ws/9CVo

Fondo Monetario Internacional (FMI). (2020). Una crisis como ninguna otra, una recuperación incierta. http://bitly.ws/9CVS 
Hanage, W., Qiu, X. y Kennedy-Shaffer, L. (2020). Snowball sampling study design for serosurveys in the early COVID-19 pandemic. Harvard Library Office for Scholarly Communication. http://bitly.ws/9CVL

Ivars, J., Rodríguez, I. y Vera, J. (2013). The evolution of mass tourism destinations: new approaches beyond deterministic models in Benidorm (Spain). Tourism Management, 34, 184-195. https://doi.org/10.1016/j.tourman.2012.04.009

Kotler, P., Bowen, J. y Makens, J. (2014). Marketing for hospitality and tourism. Prentice Hall.

Kuo, H., Chang, C., Huang, B., Chen, C. y McAleer, M. (2009). Estimating the impact of avian flu on international tourism demand using panel data. Tourism Economics, 15(3), 501-511. https://doi.org/10.2139/ssrn.1365228

Mazanec, J. y Ring, A. (2011). Tourism destination competitiveness: second thoughts on the World Economic Forum reports. Tourism Economics, 17(4), 725751. https://doi.org/10.5367/te.2011.0065

Monterrubio, J. C. (2010). Short-term economic impacts of influenza AH1N1 and government reaction on the Mexican tourism industry: an analysis of the media. International Journal of Tourism Policy, 3(1), 1-15. https://doi.org/10.1504/ IJTP.2010.031599

Oliver, R. (1999). Whence consumer loyalty. Journal of Marketing [Special issue], 63, 33-44. https://doi.org/10.1177/00222429990634s105

Organización Mundial de la Salud (OMS). (2010). ¿Qué es una pandemia? http://bitly. ws/9CVH

Organización Mundial del Turismo (OMT). (2019). Panorama del turismo mundial 2019. https://www.e-unwto.org/doi/pdf/10.18111/9789284421237.

Pike, S. (2012). Destination positioning opportunities using personal values: elicited through the repertory test with laddering analysis. Tourism Management, 33(1), 100-107. https://doi.org/10.1016/j.tourman.2011.02.008

Rassy, D. y Smith, R. (2013). The economic impact of H1N1 on Mexico's tourist and pork sectors. Health Economics, 22(7), 824-834. https://doi.org/10.1002/ hec.2862 
Ritchie, J. B. y Crouch, G. I. (2005). The competitive destination: A sustainable tourism perspective. Cabi.

Salvador-Figueras, M. (2003). Análisis de correspondencias. 5campus.com. http:// www.5campus.com/leccion/correspondencias.

Secretaría de Hacienda y Crédito Público (SHCP). (2020). Informe sobre la situación económica. http://bitly.ws/9CVG.

Sheldon, P. y Dwyer, L. (2010). The global financial crisis and tourism: perspectives of the academy. Journal of Travel Research, 49(1), 3-4. https://doi. org/10.1177/0047287509353191

Svensson, B., Moreno, P. y Martín, D. (2011). Understanding travel expenditure by means of market segmentation. The Service Industries Journal, 31(10), 16831698. https://doi.org/10.1080/02642069.2010.503891

Thrane, C. y Farstad, E. (2011). Domestic tourism expenditures: the non-linear effects of length of stay and travel party size. Tourism Management, 32(1), 46-52. https://doi.org/10.1016/j.tourman.2009.11.002

Vu, J. y Turner, L. (2011). Shift-share analysis to measure arrivals competitiveness: the case of Vietnam, 1995-2007. Tourism Economics, 17(4), 803-812. https:// doi.org/10.5367/te.2011.0070

Wilder-Smith, A. (2006). The severe acute respiratory syndrome: impact on travel and tourism. Travel Medicine and Infectious Disease, 4(2), 53-60. https://doi. org/10.1016/j.tmaid.2005.04.004

World Travel \& Tourism Council (WTTC). (2019). Crisis readiness. Are you prepared and resilient to safeguard your people and destinations? https://www.globalrescue.com/grmkt_resources/pdfs/Crisis-Readiness-Final.pdf.

Zieba, M. (2017). Cultural participation of tourists. Evidence from travel habits of Austrian residents. Tourism Economics, 23(2), 295-315. https://doi. org/10.1177/1354816616656264 